\title{
3D Finite Element Modelling of Sheet Pile Wall Excavation: A Case study in Bangkok
}

\author{
Chhunla Chheng ${ }^{1 *}$, Suched Likitlersuang ${ }^{2, *}$ \\ ${ }^{I}$ Master student, Department of Civil Engineering, Faculty of Engineering, Chulalongkorn University, Bangkok, \\ Thailand. \\ ${ }^{2}$ Professor, Geotechnical Research Unit, Department of Civil Engineering, Faculty of Engineering, Chulalongkorn \\ University, Bangkok, Thailand. \\ *Corresponding author: chhunla.ch@student.chula.ac.th,
}

\begin{abstract}
Sheet pile wall has been used extensively as a soil retaining structure during the excavation process in soft ground. Meanwhile, finite element method (FEM) has been widely used as a numerical tool to predict wall movements due to soil excavation. In FEM, many factors including soil parameters, structures' parameters and construction stages simulation influence the analysis results. This paper presents a modelling of sheet pile wall at deep excavation using 3D FEM. The study focuses on the structures' stiffness modelling and the stages of construction simulation. The hardening soil model and its parameters adopted from previous study was employed in the analysis. To validate the model, an excavation site located in the center of Bangkok was selected to model. PLAXIS 3D - a commercial software for solving finite element problem was employed in this study. In overall, the results of wall movements from 3D FEM agree well with the instrumented data confirming that the modelling could reflect the real behavior of sheet pile walls at deep excavation in soft soils in Bangkok.
\end{abstract}

Keywords - 3D Finite element analysis, Deep excavation, Wall deformation, Hardening soil model, stiffness parameters, Soft

\section{INTRODUCTION}

$S$ structure in excavation worldwide. It is one of the soil retaining structure which is relatively cheap and simple in installation. However, the deformation is relatively large. Hence, the behaviour of sheet piles during the excavation process needs to be assessed carefully. To estimate the deformation of sheet pile walls, a 2D finite element analysis (FEA) has been used dominantly since the past time due to the simplicity, and less time consuming though most of the projects cannot be simplified as 2D problem.

At present, computers are becoming more powerful which benefits the utilization of 3D FEM in prediction of deformation of sheet piles. Modelling of a crooked cross sectional area of sheet piles in 3D FEM is not simple by just input the stiffness parameters directly. Therefore, this study aims to provide the guideline to model sheet piles in 3D FEM which will provide accurate wall deformation predictions by comparing with field data. PLAXIS 3D - a commercial software is employed in this study. A case study of Siam Motor Machine Buiding available in [2] constructed in Bangkok is selected. The underground excavation depth is about $7.2 \mathrm{~m}$ deep below ground and the excavaton area are rectangle with $58.7 \mathrm{~m}$ long and $32.8 \mathrm{~m}$ wide as shown in Figure 1. Two inclinometers installed at long and short sides of the excavation are considered.

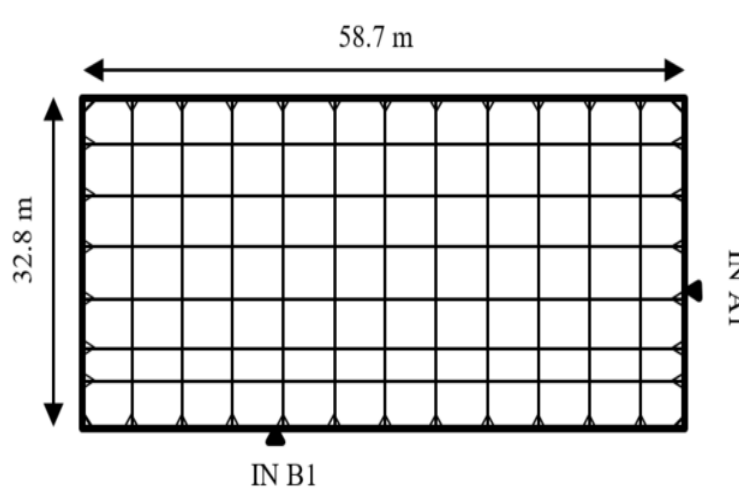

Figure 1. Layout of Siam Motor Machine Building

\section{BANGKOK SUBSOIL CONDITION}

Bangkok is located on the low flat of Chao Praya Delta in the central plain region of Thailand. The soil layers are generally divided into 7 different layers including Made Ground (MG), Bangkok Soft Clay (BSC), Medium Clay (MC), First Stiff Clay (1st SC), Clayey Sand (CS), Second Stiff Clay (2nd SC) and Hard Clay (HC) [3]. The constitutive modelling for soils used in this study is Hardening soil model (HSM), an advanced soil model for describing both soft and stiff soils [4]. It adopts well-known hyperbolic model developed by [5] and Mohr-Coulomb failure criterion. The complete set of soil parameters for HSM was reported by Likitlersuang, et al. [1] as shown in Table 1. 
Moreover, Bangkok groundwater condition suffered from deep well pumping leading to drawdown of pore water pressure as in Figure 1.

Table 1: Hardening soil model parameters (after Likitlersuang, et al. [1])

\begin{tabular}{ccccccccccccccccc}
\hline Soil type & $\begin{array}{c}\gamma_{b} \\
\left(\mathrm{kN} / \mathrm{m}^{3}\right)\end{array}$ & $\begin{array}{c}c^{\prime} \\
(\mathrm{kPa})\end{array}$ & $\begin{array}{c}\phi^{\prime} \\
\left(^{\circ}\right)\end{array}$ & $\begin{array}{c}\psi^{\prime} \\
\left.{ }^{\circ}\right)\end{array}$ & $\begin{array}{c}E_{50}^{r e f} \\
(\mathrm{MPa})\end{array}$ & $\begin{array}{c}E_{\text {oed }}^{r e f} \\
(\mathrm{MPa})\end{array}$ & $\begin{array}{c}E_{u r}^{r e f} \\
(\mathrm{MPa})\end{array}$ & $v_{u r}$ & $m$ & $K_{0}^{n c}$ & $R_{f}$ & $R_{\text {inter }}$ & $\begin{array}{c}\text { Analysis } \\
\text { type }\end{array}$ \\
\hline MG & 18 & 1 & 25 & 0 & 45.6 & 45.6 & 136.8 & 0.2 & 1 & 0.58 & 0.9 & 0.7 & Drained \\
BSC & 16.5 & 1 & 23 & 0 & 0.8 & 0.85 & 8.0 & 0.2 & 1 & 0.7 & 0.9 & 0.7 & Undrained \\
$1^{\text {st }}$ SC & 19.5 & 25 & 26 & 0 & 8.5 & 9.0 & 30.0 & 0.2 & 1 & 0.5 & 0.9 & 0.7 & Undrained \\
CS & 19 & 1 & 27 & 0 & 38.0 & 38.0 & 115.0 & 0.2 & 0.5 & 0.55 & 0.9 & 0.7 & Drained \\
\hline
\end{tabular}

Pore Water Pressure $(\mathrm{kN} / \mathrm{m} 2)$

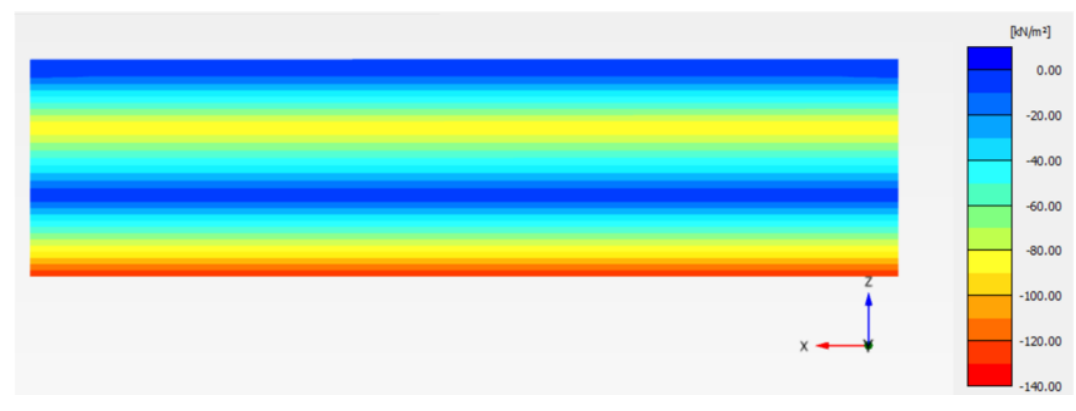

(a)

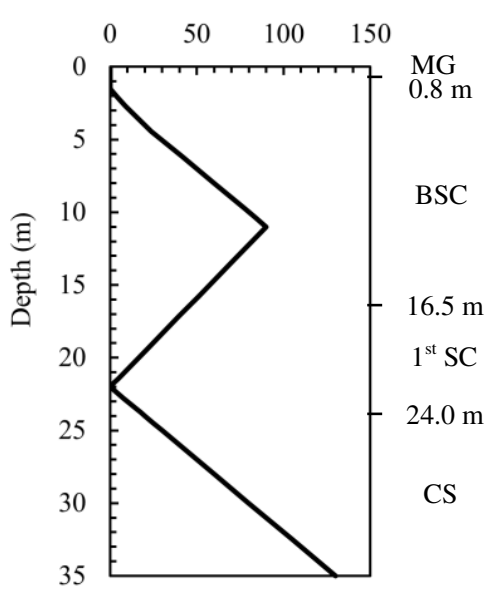

(b)

Figure 2. Pore water pressure profile at initial condition from 3D FEA. (a) Shading view. (b) Extracted values.

:et pile's

\section{SOIL RETAINING STRUCTURES MODELLING}

Excavation was supported by $18 \mathrm{~m}$-long sheet pile wall and 3 levels of strutting system. Sheet piles possess a complex and non-symmetrical cross-section. However, plate elements are used to model the sheet piles in 3D FEM. The crooked sectional area of sheet piles are simplified into straight surface plate element and stiffness parameters are adjusted using following equations adopted from [6] and its values are presented in Table 2. Struts and wailings were also used in this projects to provide lateral supports to sheet piles. Their axial and flexural stiffnesses are major properties which are reasonably modelled as beam element in FEM. Their input parameters are also summarized in Table 2.

$$
\begin{aligned}
& d=h \\
& \gamma=A \gamma_{\text {steel }} / d \\
& E_{1}=12 E_{\text {steel }} I / d^{3} \\
& E_{2} \approx E_{1} / 20 \\
& v \approx 0 \\
& G_{12} \approx 6 E_{\text {steel }} I / 10 d^{3} \\
& G_{13} \approx E_{\text {steel }} A / 6 d \\
& G_{23} \approx E_{\text {steel }} A / 20 d
\end{aligned}
$$

where $d$ is the equivalent thickness of the plate, while $h$ cross section respectively. $\gamma$ is the unit weight of plate and $\gamma_{\text {steel }}$ is the unit weight of sheet piles. $E_{\text {steel }}$ and $I$ are Young's modulus and moment of inertia per wall width of the sheet piles. $E$ and $G$ on the left sides of the equations are modulus of elasticity and shear modulus of plate orderly. The numbers represent the directions or plans to which they are respected. The vertical, longitudinal, and transversal directions are denoted as 1 , 2 , and 3, respectively. $v$ is Poisson's ratio and assumed as zero in the study as recommended by [6]. Further details of sheet pile models can be found in [6].

\section{CONSTRUCTION SEQUENCES}

Underground construction of this project started by installation of sheet piles surrounding the excavation area. Then the excavation was started by first excavation to the depth of $1.50 \mathrm{~m}$ below ground level. The surcharge was also applied at early stage. Before proceeding the excavation to the depth of $3.9 \mathrm{~m}$, the bracing was installed at level of $0.8 \mathrm{~m}$ deep $\left(1^{\text {st }}\right.$ level). Later, prior to the excavation to $5.8 \mathrm{~m}$ deep, the bracing was installed at level $2.9 \mathrm{~m}$ below level 0.00 ( $2^{\text {nd }}$ level $) .3^{\text {rd }}$ level of strut was installed at $5.1 \mathrm{~m}$ deep before the excavation reached the final depth of $7.2 \mathrm{~m}$. These construction stages are summarized in Table 3. The finite element mesh as shown in Figure 3 consists of 139,957 tetrahedral elements with the average dimension of 1.96 m. 
Table 2: Parameters for structural models

\begin{tabular}{cccc}
\hline & & & \\
Parameters & $\begin{array}{c}\text { Sheet piles } \\
\text { (FSP }-\mathrm{IV})\end{array}$ & $\begin{array}{c}\text { Steel Struts } \\
(300 \times 300 \times 172 \mathrm{~kg} / \mathrm{m})\end{array}$ & $\begin{array}{c}\text { Steel Wailings } \\
(400 \times 400 \times 172 \mathrm{~kg} / \mathrm{m})\end{array}$ \\
\hline$d(\mathrm{~m})$ & & - & - \\
$A\left(\mathrm{~m}^{2}\right)$ & 0.17 & $1.20 \times 10^{-2}$ & $2.19 \times 10^{-2}$ \\
$\gamma\left(\mathrm{kN} / \mathrm{m}^{3}\right)$ & - & 78.50 & 78.50 \\
$E(\mathrm{kPa})$ & - & $200 \times 10^{6}$ & $200 \times 10^{6}$ \\
$E_{1}(\mathrm{kPa})$ & $188.60 \times 10^{6}$ & - & - \\
$E_{2}(\mathrm{kPa})$ & $9.42 \times 10^{6}$ & - & - \\
$I_{3}\left(\mathrm{~m}^{4}\right)$ & - & $6.75 \times 10^{-5}$ & $2.66 \times 10^{-4}$ \\
$I_{2}\left(\mathrm{~m}^{4}\right)$ & - & $2.04 \times 10^{-4}$ & - \\
$v$ & 0 & - & - \\
$G_{12}(\mathrm{kPa})$ & $9.42 \times 10^{6}$ & - & - \\
$G_{13}(\mathrm{kPa})$ & $4.75 \times 10^{6}$ & - & - \\
$G_{23}(\mathrm{kPa})$ & $1.42 \times 10^{6}$ & - & - \\
\hline $\mathrm{Sur}$ & & &
\end{tabular}

Surcharge: 5 and $10 \mathrm{kN} / \mathrm{m}^{2}$

Table 3: Construction sequences

\begin{tabular}{cl}
\hline Stage & \multicolumn{1}{c}{ Construction activities } \\
\hline 1 & Wish-in-place of sheet pile walls and excavation to $-1.50 \mathrm{~m}$ \\
2 & Installation $1^{\text {st }}$ level struts and wailings and excavation to $-3.90 \mathrm{~m}$ \\
3 & ${\text { Installation 2 } 2^{\text {nd }} \text { level struts and wailings and excavation to }-5.80 \mathrm{~m}}^{\text {rd }}$ level struts and wailings and excavation to $-7.20 \mathrm{~m}$ \\
\hline
\end{tabular}

Surcharge is applied.

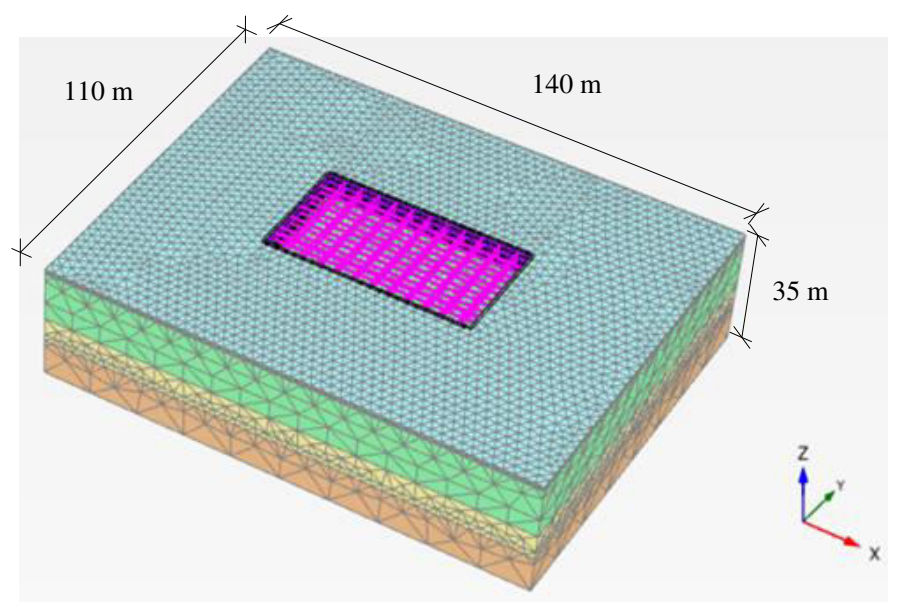

Figure 3. Finite element mesh of Siam Motor Machine Building

\section{RESULTS AND DISCUSSIONS}

3D FEA provides the results of wall deformation at all locations around the excavation site as displayed in Figure 4. The shading view shows that the lateral wall movement increases with the stage of excavation. As two inclinometers were installed at the short and long side of excavation, the readings are used to compare with the simulation results. To consider the value of the movement, cross sections are cut as in Figure 5, and the values at all stages of excavation are plotted against depth as depicted in Figure 6(a) and (b) for short side and long side of retaining walls respectively with the comparison to the measured field data. It can be seen that the shape of deformations of all stages completely agree with the in-situ situation as reported by inclinometers readings.
Cantilever types of wall movements can be observed at stage 1, while deep inward types are seen at later stages of excavation after the bracing system was installed. These observations agree with the observation from Clough and O'Rourke [7]. Figure 6(a) depicts the values of wall movements and comparison with instrumented data from IN A1 at all 4 stages of modelling. The maximum lateral wall movements are $90 \mathrm{~mm}, 100 \mathrm{~mm}$, $145 \mathrm{~mm}$, and $193 \mathrm{~mm}$ at stage 1 to 4 , respectively comparing to $50 \mathrm{~mm}, 105 \mathrm{~mm}, 149 \mathrm{~mm}$, and $187 \mathrm{~mm}$ from IN A1. Figure 6(b) presents the results of lateral wall movements on the long side from 3D FEA comparing with inclinometer number B1 (IN B1). The maximum lateral wall movements are $136 \mathrm{~mm}, 140 \mathrm{~mm}$, $172 \mathrm{~mm}$ and $216 \mathrm{~mm}$ from stage 1 to 4 orderly. The inclinometer was read at $78 \mathrm{~mm}, 37 \mathrm{~mm}, 213 \mathrm{~mm}$ and $222 \mathrm{~mm}$ for stage 1 to 4 respectively. 


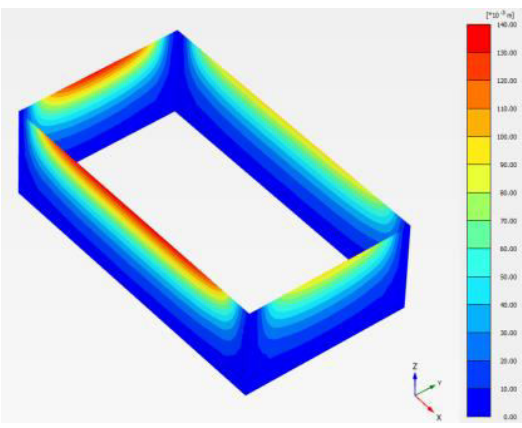

(a)

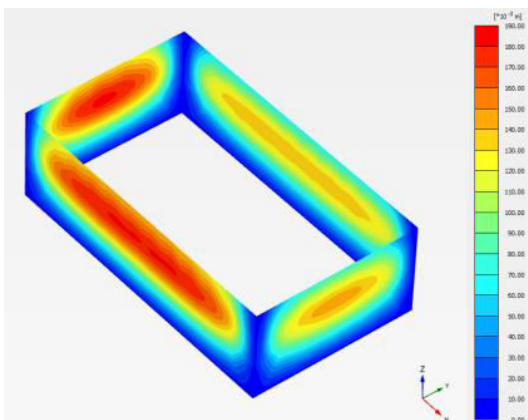

(c)

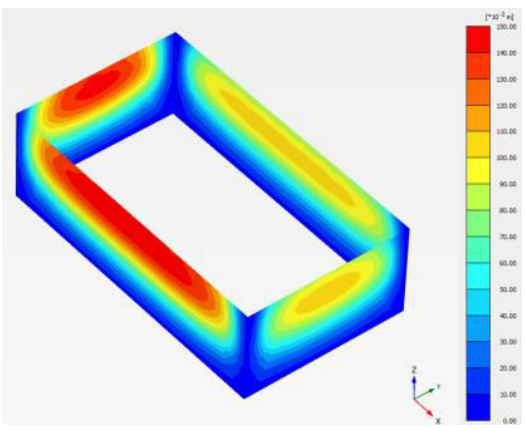

(b)

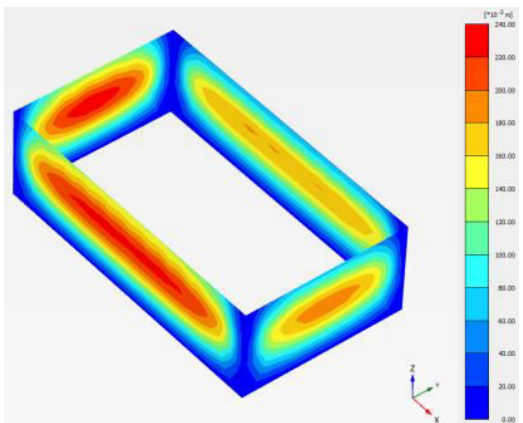

(d)

Figure 4. Wall deformations: (a). Stage 1. (b) Stage 2. (c) Stage 3. (d) Stage 4

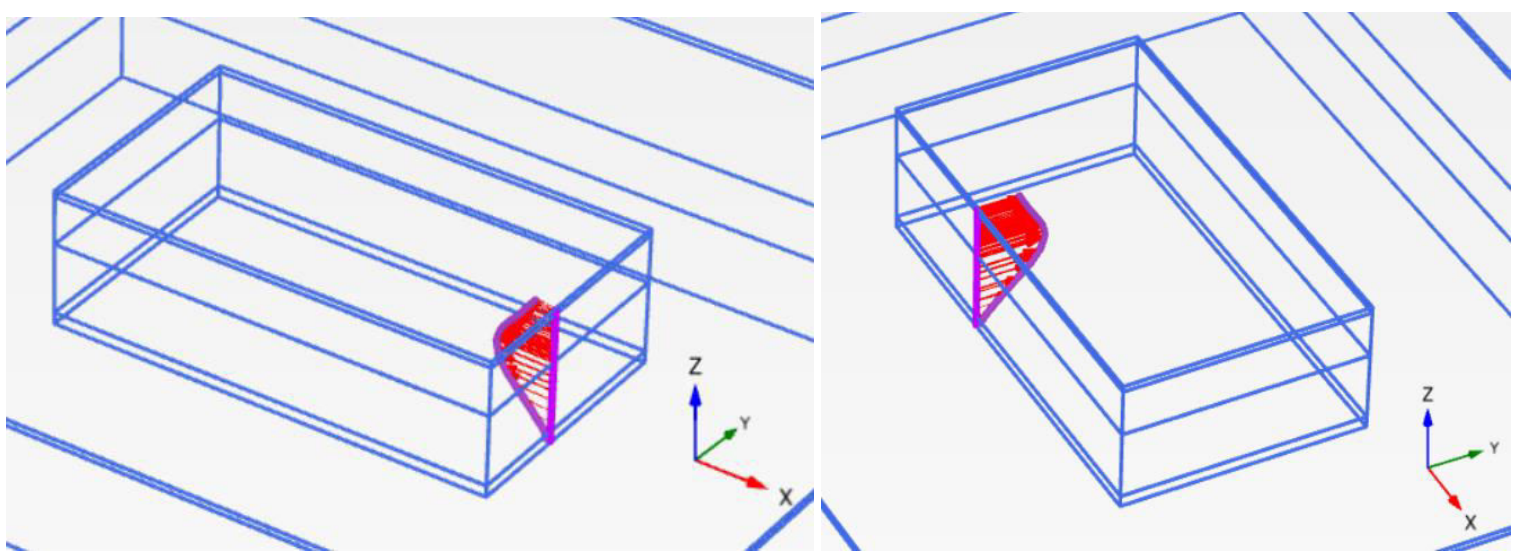

(a)

(b)

Figure 5. Lateral wall movement at stage 4 by PLAXIS 3D [movement $\times 40$ ]. (a) On the short side (IN A1). (b) On the long side (IN B1).

Both locations reveal that the differences are as less as $10 \%$ except the stage 1 of excavation which may be caused by the installation effect.

Furthermore, Figure 7(a) depicts the values of the lateral wall movements at the middle of the long wall where the largest lateral wall movement occurs. The wall movements at 4 stages are plotted. Moreover, the ground surface settlement corresponding to the largest lateral wall movement at stage 4 from 3D FEM and the trilinear empirical relationship of ground surface settlement proposed by [8] are plotted in Figure 7(b).
The maximum ground surface settlement at final stage is $207 \mathrm{~mm}$ which is about 0.9 time the maximum lateral wall movement at the corresponding stage of analysis.In this mean time, the upper limit by [9] was 1 . Hence, the 3D FEM for sheet pile walls is confirmed reasonable and accurate 


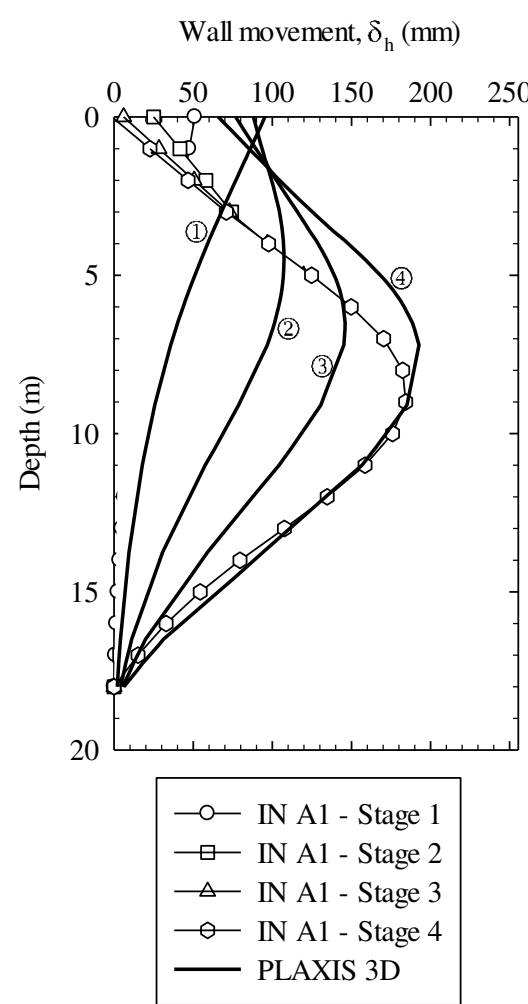

(a)

Wall movement, $\delta_{\mathrm{h}}(\mathrm{mm})$

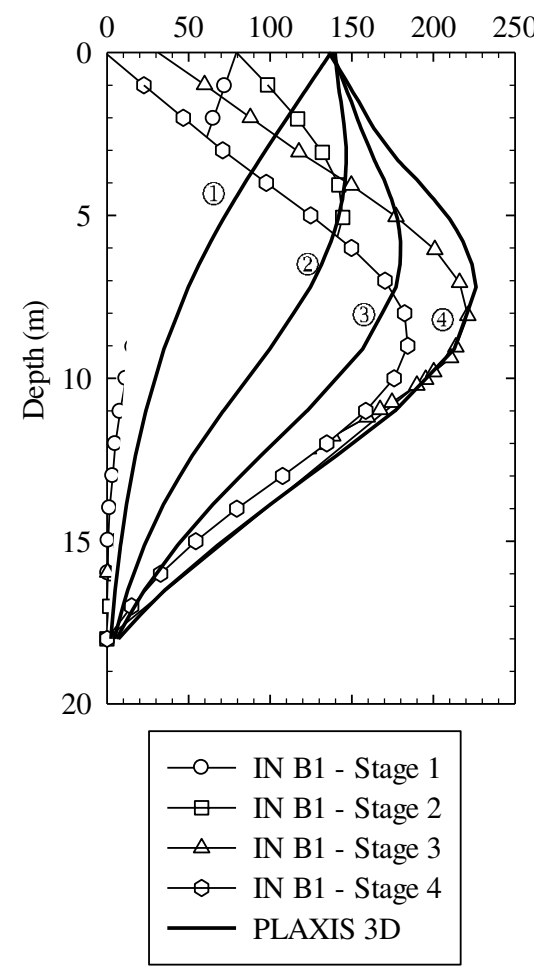

(b)

Figure 6. Lateral wall movements: (a) 3D FEA vs. IN A1. (b) 3D FEA vs IN B1.

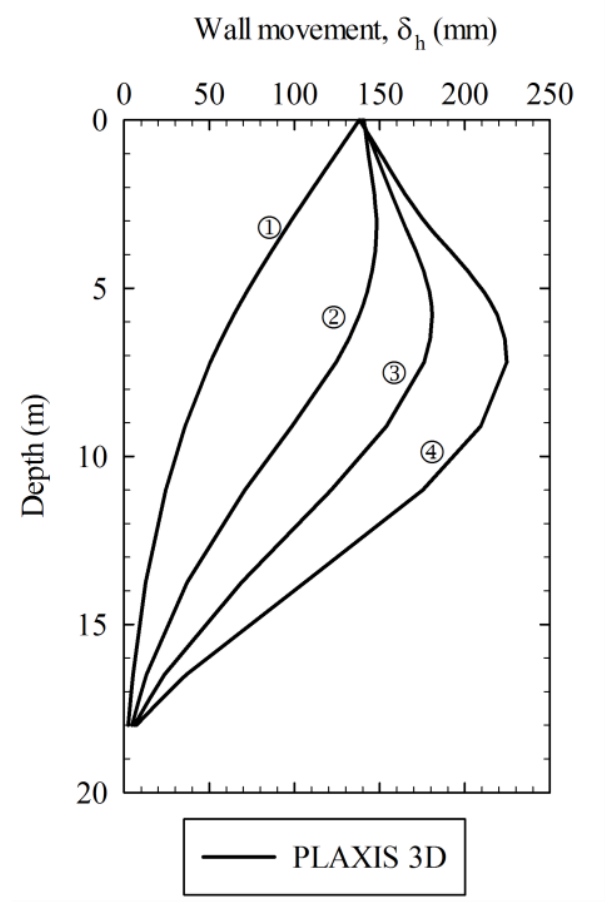

(a)

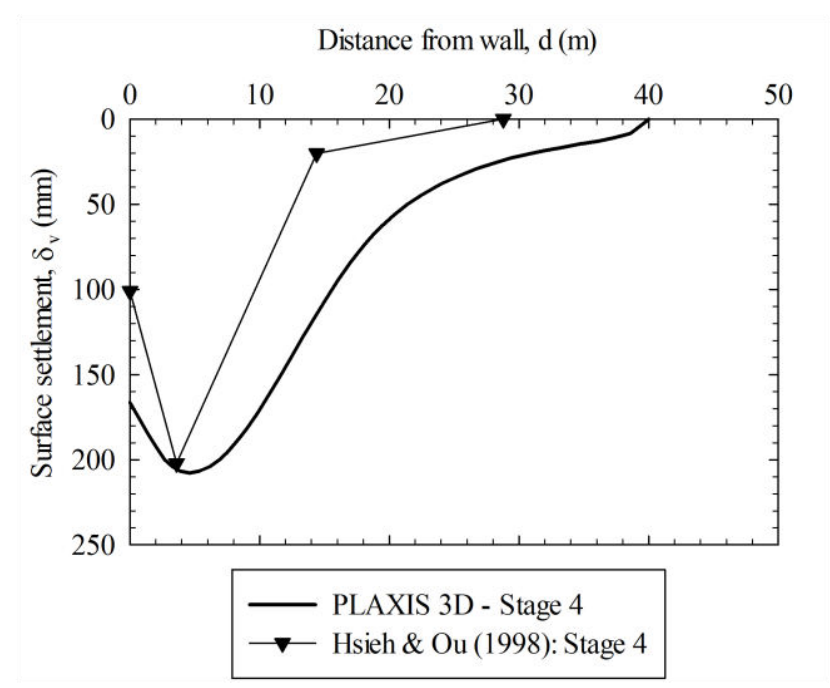

VI. CONCLUSIONS

In conclusion, 3D FEM can be applicable for deep excavation analysis to predict the lateral wall movements of sheet piles. The modified stiffness parameters of sheet piles provided accurate prediction of wall movement as

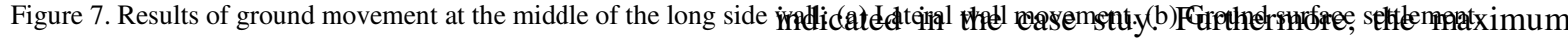
ground surface settlement from 3D FEM agreed well with the empirical relationship. In overall, the 3D FEM will predict ground movements in excavation which is 
retained by sheet pile wall accurately provided that all relevant parameters including soil parameters, choice of constitutive modelling, pore water pressure modelling, structural materials parameters determination, and construction sequences are considered correctly in the 3D FEM in order to get accurate wall deformation prediction.

\section{ACKNOWLEDGEMENT}

The first author wishes to thank the AUN/SEED-Net

(JICA) for a scholarship during his study. Authors would like to thank Geotechnical Research Unit (GRU) of Chulalongkorn University for the software PLAXIS license support.

\section{REFERENCES}

[1] S. Likitlersuang, C. Surarak, D. Wanatowski, E. Oh, and A. Balasubramaniam, "Finite element analysis of a deep excavation: A case study from the Bangkok MRT," Soils and Foundations, vol. 53, pp. 756-773, 2013.

[2] T. Sutabutr, "Deformation Analysis of Deep Excavation in Bangkok Subsoils," Master's Thesis, Asian Institute of Technology, Thailand, 1992.

[3] S. Likitlersuang, C. Surarak, D. Wanatowski, E. Oh, and A. Balasubramaniam, "Geotechnical parameters from pressuremeter tests for MRT Blue Line Extension in Bangkok," Geomechanics and Engineering: An International Journal, vol. 5, pp. 99-118, 2013.

[4] T. Schanz, P. Vermeer, and P. Bonnier, "The hardening soil model: formulation and verification," Beyond 2000 in computational geotechnics, pp. 281-296, 1999.

[5] J. M. Duncan and C. Y. Chang, "Nonlinear analysis of stress and strain in soils," Journal of the Soil Mechanics and Foundations Division, ASCE, vol. 96, pp. 637-659, 1970.

[6] R. B. J. Brinkgreve, S. Kumarswamy, W. M. Swolfs, D. Waterman, A. Chesaru, P. G. Bonnier, et al., "PLAXIS 2015," PLAXIS bv, The Netherlands, 2015.

[7] G. W. Clough and T. D. O'Rourke, "Construction-Induced Movements of Insitu Walls," in Design and Performance of Earth Retaining Structures, 1990, pp. 439-470.

[8] P.-G. Hsieh and C.-Y. Ou, "Shape of ground surface settlement profiles caused by excavation," Canadian geotechnical journal, vol. 35 , pp. 1004-1017, 1998

[9] A. I. Mana and G. W. Clough, "Prediction of movements for braced cuts in clay," Journal of Geotechnical Engineering Division, ASCE, vol. 107, pp. 759-777, 1981. 